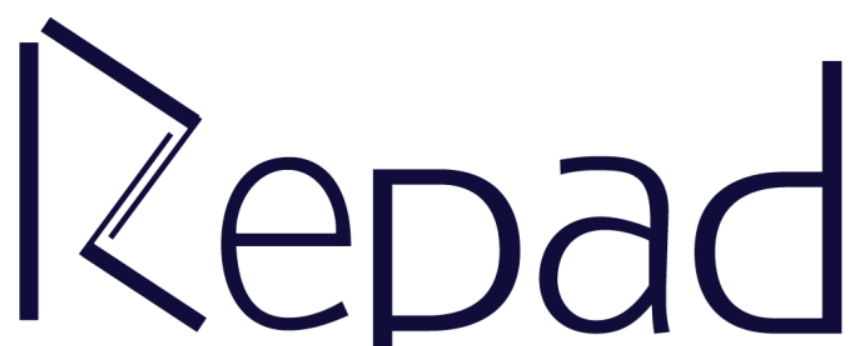

v. 5 , n. 2, Maio-Agosto/2021

Revista Estudos e

Pesquisas em Administração

(cC) (i) This work is licensed under a Creative Commons Attribution 4.0 International License 


\title{
A INSERÇÃO LABORAL DURANTE O CURSO UNIVERSITÁRIO: A realidade dos estudantes de administração de uma instituição pública
}

\author{
Fernanda Segui \\ fersegui28@gmail.com \\ https://orcid.org/0000-0003-0752-3915 \\ http://lattes.cnpq.br/8025355154236603 \\ Universidade Estadual do Centro Oeste, Unicentro \\ Guarapuava, Paraná, Brasil \\ Márcio Luiz Bernardim \\ marcio@unicentro.br \\ https://orcid.org/0000-0003-3639-7938 \\ http://lattes.cnpq.br/0503194694586499 \\ Universidade Estadual do Centro Oeste, Unicentro \\ Guarapuava, Paraná, Brasil \\ Sílvio Roberto Stefano \\ silviostefano@unicentro.br \\ https://orcid.org/0000-0002-5871-8686 \\ http://lattes.cnpq.br/0852434853164544 \\ Universidade Estadual do Centro Oeste, Unicentro \\ Guarapuava, Paraná, Brasil
}

\section{Resumo}

Esta pesquisa trata da inserção dos alunos do curso de graduação em administração no mercado de trabalho. O objetivo foi identificar como se dá a inserção profissional dos estudantes, além de conhecer as suas expectativas quanto ao futuro profissional e educacional. O estudo da transição da vida estudantil para a vida laboral pode contribuir para a compreensão das dificuldades enfrentadas pelos jovens trabalhadores e para a geração de uma rede de apoio para reduzir o abandono escolar e facilitar o ingresso no mercado de trabalho. Os resultados da pesquisa survey com os estudantes apontaram que eles desenvolvem alguma atividade laboral, seja por meio de estágio ou de contratação formal ou informal, mas enfrentam inúmeras dificuldades para conciliar estudo e trabalho. Por outro lado, quanto mais precoce começam a trabalhar, mais experiência adquirem e menos dificuldade enfrentam na procura de emprego depois de formados, ainda que isso não signifique melhor renda. A pesquisa também revela que o interesse em obter trabalho qualificado e melhores níveis de renda impulsionam os estudantes para um processo de formação continuada, o que se percebe pelo interesse de continuar estudando mesmo depois de concluído o curso de administração.

Palavras-chave: Emprego. Trabalho. Estudantes universitários. Curso de administração. 


\title{
WORK INSERTION DURING THE UNIVERSITY COURSE: The reality of administration students at a public institution
}

\begin{abstract}
The present research deals with the insertion of undergraduate Administration students in the labor market. The objective was to identify how the students' professional insertion occurs, besides knowing their expectations regarding the professional and educational future. Studying the transition from student to working life can contribute to the understanding of the difficulties faced by young workers, as well as to the generation of a support network to reduce school dropout and to facilitate entry into the labor market. The results of the survey with students showed that they carry out some work activity, either through internship or through formal or informal hiring, however they also face numerous difficulties to reconcile study and work. On the other hand, the earlier they start working, the more experience they acquire and the less difficulty they face in looking for a job after they graduate, even if that does not mean better income. The survey also reveals that the interest in obtaining qualified work and better income levels propel students to a process of continuing education, what is possible to verify by the interest in continuing to study even after completing the Administration course.
\end{abstract}

Keywords: Employment. Work. Undergratuate students. Administration course.

Submetido: $27 / 03 / 2021$

Revisões Requeridas: 31/07/2021

Aceito: $04 / 08 / 2021$

Publicado: 31/08/2021

\section{INTRODUÇÃO}

É comum que os jovens que se inserem no meio universitário o façam almejando uma formação que contribua para sua introdução ou permanência no mercado de trabalho. Muitos acreditam que o curso de administração pode abrir várias oportunidades de emprego com bons salários, em grandes companhias, ou capacitá-los para abertura do seu próprio negócio, embora o desenvolvimento desse potencial empreendedor demande grande esforço não só dos próprios alunos como também da universidade (PIETROVSKI et al., 2019).

A maioria dos que iniciam o curso focam na carreira profissional, acreditando que o diploma será a ponte para o sucesso, embora essa relação de causa-efeito precise considerar a sintonia da formação com as demandas empresariais, conforme alertam Moreira et al. (2014).

A inserção laboral ocorre de maneiras variadas, seja por meio da efetivação em estágios ou programas de aprendizagem, seja mediante a conquista de um emprego ou o início de um empreendimento próprio após a graduação. Além disso, diferentemente da falta de interesse pelas licenciaturas, que visam à formação para o magistério (ALMEIDA et al., 2014), depois de ingressarem em cursos de bacharelado, como o de administração, parece que a perspectiva de atuação na docência motiva os estudantes para o prosseguimento dos estudos. 
O empreendedorismo é outra possibilidade de ingresso no mercado, pois muitos pequenos negócios surgem justamente da necessidade de conciliar a busca de experiência com a obtenção de renda. Se por um lado e especialmente para os mais pobres as políticas públicas focadas na qualificação para um emprego e na busca da empregabilidade representam o caminho mais acessível (TOMMASI; CORROCHANO, 2020), também é preciso considerar que o empreendedorismo nos moldes tradicionais já não apresenta os resultados esperados para os dias de hoje. É necessário articular a ação de empreender com as ações de inovar e trabalhar em redes (VALE; WILKINSON; AMÂNCIO, 2008).

Essa expectativa de muitos estudantes reforça os achados do estudo de Ferreira e Abranches (2018), os quais discutem a inserção dos egressos de administração no mercado de trabalho e o possível impacto que o conhecimento tem sobre os seus rendimentos. Jacob e Weiss (2010) realizaram um estudo empírico longitudinal destacando que a transição do ensino superior para o mercado de trabalho envolve variadas situações, que são menos padronizadas nos EUA e mais regulamentadas na Alemanha, por exemplo. Quando pesquisaram a percepção de estudantes de administração sobre fatores que contribuem para o aprendizado, Fontanini, Wollmann e Chiesa (2019) detectaram que há necessidade de uma articulação consistente entre os fatores "professor", "estudante" e "universidade", com destaque para o primeiro. Tais estudos revelam que as relações de causa e efeito em termos de aprendizado e oportunidades de emprego e renda são complexas e dependem de uma conjugação de esforços e fatores que se somam para o objetivo desejado.

O desenvolvimento desta pesquisa foi motivado pela busca de respostas para as seguintes questões: Como se dá o ingresso dos universitários no mercado de trabalho? Quais as dificuldades encontradas pelos estudantes na caminhada até a inserção profissional? Tais questões ecoam os conflitos vividos pelos próprios alunos, que têm dúvidas se o tempo e o esforço investidos na formação universitária darão os resultados esperados. Também podem lançar luz sobre lacunas ainda existentes na literatura, como: a percepção dos próprios alunos sobre sua trajetória estudantil e profissional e sobre a vinculação existente entre elas; as estratégias desenvolvidas para enfrentar as dificuldades sentidas nessa trajetória.

Pesquisar a formação universitária e os possíveis encaminhamentos profissionais é uma necessidade em tempos de precarização e vulnerabilidades dos jovens quanto à obtenção de trabalho e renda, conforme mostram estudos inclusive na União Europeia (MARQUES, 2020). O curso de administração pode abrir muitas portas, pois traz em seu repertório um amplo leque de opções para atuação em áreas diversificadas, como Gestão de Pessoas, Finanças, Marketing, Logística, entre outras. Logo, se em tese há mais oportunidades de trabalho para os estudantes dessa carreira, é necessário investigar se isso se comprova na prática, e nos casos em que há dificuldades, como elas efetivamente são enfrentadas.

O principal objetivo do estudo foi, portanto, identificar as formas de inserção profissional dos estudantes universitários do curso de administração, além de conhecer as suas expectativas quanto ao futuro profissional e educacional. Nesse percurso, foi possível ampliar a compreensão de que há variadas situações nessa transição da vida escolar para a vida profissional, e que se para alguns esse percurso ocorre sem maiores problemas, para a maioria os obstáculos são enormes, começando já no momento de conciliar estudo e trabalho. Além disso, o estudo mostrou-se oportuno, contribuindo 
para a geração de conhecimentos novos a respeito de um tema que interessa a todos: estudantes, professores, universidade, empresários.

\section{REFERENCIAL TEÓRICO}

Quando o objetivo é estudar como se dá transição estudo-trabalho na vida de universitários, é importante antes considerar o papel do trabalho na vida desse público. Oliveira, Piccinini e Silveira (2010) empreenderam um estudo com alunos de administração para verificar a representação social presente na sua fala quanto se referem à palavra trabalho. Essa transição para a vida adulta, que marca inclusive o período de escolha e ingresso na universidade, os jovens sofrem diversas modificações, tanto mental quanto física e psicológica. Os autores mostram que, de modo geral, o trabalho continua a ocupar um lugar central no conjunto das atividades das pessoas e da sociedade, sendo um elemento de integração social, de inserção e promoção da realização profissional e financeira.

Tanto o valor do trabalho para os jovens quanto as motivações que os levam a buscar formação para o exercício de uma ocupação/profissão são aspectos importantes a serem considerados na análise da transição da vida de estudante dependente dos pais para a vida de trabalhador/profissional independente. A pesquisa realizada por Chaves, Ramos e Santos (2016), em duas universidades de Lisboa, que levou em conta as orientações intrínsecas e extrínsecas e suas relações com as condições materiais de existência dos estudantes, revelou a coexistência de três padrões explicativos dessas motivações: a supervalorização das aspirações, a busca de autonomia financeira frente à família e a maior valorização das recompensas intrínsecas que às extrínsecas.

Assim, é natural que antes mesmo de se formar os estudantes busquem campos de emprego em suas áreas, relacionando sua capacidade profissional com a compreensão conceitual da inserção no trabalho. Logo, a relação entre experiência escolar e escolha de carreira acadêmica pode trazer ao jovem empregado os conhecimentos e a desenvoltura necessários para as atividades desenvolvidas/enfocadas na sua área de formação. Foi isso que o estudo empreendido por Rueda, Martins e Campos (2004) procurou compreender ao abordar jovens e adultos (estudantes ou já graduados), pesquisando como eles entendem o conceito de empregabilidade e como veem o mercado de trabalho tendo em vista as suas expectativas de carreira.

Essa compreensão do percurso a ser trilhado para se obter trabalho e renda passa também pelas condições em que se encontra o mercado de trabalho. Nesse caso, porte, características e estratégias desenvolvidas pelas organizações na contratação de trabalhadores e na formação do seu quadro de pessoal são importantes para a definição do perfil do trabalhador requerido (FERREIRA; KUHN; KAIBER; ALVES, 2019). Se por um lado o avanço na escolaridade e a obtenção de um diploma de nível superior sempre foram considerados fatores importantes para o ingresso nas ocupações mais qualificadas, nas últimas décadas a mudança estrutural no sistema de produção capitalista levou à ressignificação ou "ressimbolização" do trabalho e do poder que ele tem sobre as novas gerações, conforme termo cunhado por Marques (2009). Essa autora elenca quatro processos distintos que se complementam para explicar a vulnerabilidade laboral da classe trabalhadora na contemporaneidade, aí incluídos os jovens: a) a "cultura do risco" e a maior responsabilização dos atores, que precisam conviver em um 
ambiente de elevado grau de flexibilidade (laboral, produtiva, mercadológica, salarial etc.); b) intensificação e racionalização sob uma ótica não-taylorista da organização do trabalho, com individualização dos contratos e foco na eficácia; c) não homogeneização ou linearidade na profissionalização, concentrando-se nos arranjos e soluções situacionais específicas e responsabilização individual para as demandas do trabalho; d) incorporação da reversibilidade ou reconversão dos processos formativos como meio para a manutenção da empregabilidade e ampliação geográfica do conceito de mercado de trabalho. Assim, esses processos geram dualidades que se antagonizam entre incluídos/excluídos, estáveis/precários, empregados/desempregados, ativos/inativos, jovens/idosos etc., o que faz emergir entre os trabalhadores a insensibilidade ou a quebra da solidariedade, fruto da fragmentação e do estranhamento entre aqueles que se põe no mercado como iguais, mas que são ressignificados ou ressimbolizados pelas diferenças com as quais se apresentam ao mercado.

Nesse contexto, resta aos trabalhadores a busca da tal empregabilidade, sem a qual não conseguem se inserir no mercado de trabalho, situação que é bastante sentida pelos jovens. De acordo com Minarelli (2010), são seis os pilares que sustentam a empregabilidade, a saber: adequação vocacional (afinidade e prazer); competência profissional (capacitação pelo estudo ou experiências); idoneidade (que gera confiança); saúde física, mental e espiritual (equilíbrio entre trabalho e vida pessoal); reserva financeira (necessária para os momentos em que precisa investir em si mesmo); relacionamento (rede de contatos que constitui o capital social). Tomando como referência esses pilares, uma pesquisa feita por Ferreira Filho, Andrade e Souza (2013), com estudantes de administração de uma instituição localizada em Volta Redonda (RJ), mostrou que o pilar menos atendido pelos alunos é o da reserva financeira. Apesar disso, os acadêmicos estão conscientes da relação existente entre conhecimento e empregabilidade e que a busca da aprendizagem resultará em saberes que formarão suas competências e que serão utilizadas como estratégia para sua inserção e manutenção no mercado, o que é também respaldado pelo estudo de Ferreira, Kuhn, Kaiber e Alves (2019), as quais reforçam, todavia, a carência de oportunidades que demandem os conhecimentos e competências desenvolvidos pelos egressos de administração.

A esse respeito ganham importância as relações entre a carreira universitária buscada e as oportunidades profissionais dela decorrentes. Monteiro e Leite (2019) pesquisaram a influência da universidade sobre as decisões de carreira de estudantes de administração. Um achado interessante é que, quando analisados separadamente, os dados obtidos com os estudantes da Geração X (faixa etária de 30 a 53 anos à época da pesquisa) mostram que eles sofrem menor influência da universidade que a Geração Y (faixa etária de 18 a 30 anos à época da pesquisa), o que se explica pelo fato de terem ingressado no curso já com certa clareza quanto a sua trajetória profissional. De qualquer forma, ambos os públicos apresentam proximidade quanto a expectativas de inserção profissional, destacando-se o concurso público como a principal e o empreendedorismo como a escolha a longo prazo.

Também esclarecedora sobre essa relação dos estudantes universitários com o mercado é o estudo de Oliveira (2011), que pesquisou os alunos de administração do Estado do Rio de Janeiro, classificando-os em quatro perfis (engajado, preocupado, cético e desapegado), de acordo com o confronto com a realidade do mercado de trabalho, a confiança nas qualificações que conseguiram construir e do significado que atribuem ao trabalho, fatores estes que acabam por influenciar suas aspirações de carreira. Descobriu-se que a carreira tradicional (emprego formal numa "boa" empresa) 
ainda faz parte do imaginário da grande maioria dos entrevistados, ao mesmo tempo em que a carreira autônoma não é vista como uma alternativa viável. Assim, são poucos os que pensam numa carreira empreendedora, mas como uma alternativa para um futuro mais distante, já que ainda lhes faltaria a experiência, o capital econômico e as redes de relacionamento. Além disso, apesar de aceitarem a perspectiva de trabalhar em diferentes empresas, e não mais numa empresa só galgando postos mais importantes, os novos modelos de carreira podem gerar riscos e instabilidade que eles não estão dispostos a assumir.

Tais desconformidades entre as aspirações profissionais e as possibilidades reais de atuação profissional que vão se vislumbrando no decorrer do curso, trazem à tona as discussões sobre as frustrações que podem desembocar na evasão. Bardagi e Hutz (2012) investigaram a relação entre o mercado de trabalho, o desempenho acadêmico e o impacto sobre a satisfação universitária, revelando que a evasão escolar apresenta-se associada à falta de identidade com o curso e ao desempenho escolar, de modo que a escolha da carreira, o gosto pela profissão e a dedicação são fundamentais para o alcance do sucesso na escolha e na inserção profissional. Em estudo comparativo entre alunos mais integrados e menos integrados à universidade e ao curso escolhido, Magalhães (2013) detectou, tanto pela literatura pesquisada quanto pelos resultados obtidos na pesquisa empírica, que atitudes e crenças negativas em relação à própria capacidade acadêmica podem prejudicar o desempenho de estudantes, fragilizando sentimentos de pertencimento à comunidade universitária, o que pode diminuir a autoconfiança e enfraquecer o vínculo com a escolha do curso. Logo, o sucesso na escolha da carreira depende também da autoafirmação permanente e da determinação em relação à opção feita e o esforço para que os resultados sejam obtidos, qual seja a de uma formação consistente e que potencialize um bom ingresso profissional.

É esperado que a busca de uma graduação tenha relação com as expectativas quanto ao trabalho e à carreira a seguir. Ainda que isso nem sempre seja possível, tendo em vista as dificuldades de acessar uma área de formação que atenda a esse quesito, por motivos os mais variados, é importante que haja um esforço para relacionar a atuação profissional com a formação escolar e vice-versa, de modo a contribuir desde logo para que o objetivo traçado seja atingido. O estudo de Dias (2009) apontou justamente no sentido dessa determinação dos estudantes universitários buscando carreiras e deflagrando ações que contribuam para essa perspectiva de trabalho.

Em outra pesquisa, agora Dias e Soares (2012) mostraram que o estudante universitário se defronta, durante e após o seu percurso acadêmico, com um sentimento de insegurança quanto à área de atuação profissional. É comum a escolha pensando na possibilidade de obtenção de renda mais imediata, o que pode trazer frustrações futuras. Ainda que essas exigências econômicas sejam importantes, decisões pautadas exclusivamente por esse critério podem comprometer a realização pessoal e profissional desses indivíduos, conforme revelaram as entrevistas feitas com estudantes, mostrando tanto as realizações alcançadas quanto as insatisfações com o curso escolhido.

Mesmo assim, os esforços nem sempre proporcionam os resultados esperados, tendo em vista que há fatores externos importantes associados ao desenvolvimento individual e profissional, tais como: contextos social, educacional e político. Essa foi a preocupação de Oliveira, Detomini e Melo-Silva (2013), quando cotejaram as expectativas dos jovens ao ingressarem na universidade com as suas expectativas por ocasião da conclusão dos respectivos cursos. Os autores constaram que há dois grupos de expectativas: no primeiro grupo, que considera uma perspectiva objetiva, os 
concluintes esperam encontrar um emprego na sua área de formação, ingressar no serviço público mediante concurso ou continuar os estudos fazendo pós-graduação; no segundo grupo, que considera uma perspectiva subjetiva, os estudantes buscam satisfação com o trabalho realizado e com a utilização das competências desenvolvidas, além da possibilidade de exercer influência sobre terceiros e de se afirmar como referência na área de atuação.

O cuidado com a escolha da área profissional tem impacto sobre o grau de satisfação com a carreira. Closs e Rocha-de-Oliveira (2015) demonstraram isso quando analisaram e apresentaram a trajetória de vida de profissionais bem-sucedidos no mundo dos negócios, o que ganha relevância quando o estudo que se relata no presente artigo está voltado à área da administração. Essa área está tradicionalmente focada na capacidade de empreender e encontrar soluções para os problemas que se apresentam no mundo dos negócios. Em um cenário de desemprego e dificuldades de inserção profissional, desenvolver a capacidade empreendedora pode ser um diferencial na formação. É disso que trata a pesquisa de Cortez e Da Silva Veiga (2019), mostrando, por meio de modelos matemáticos, que os estudantes da área de sociais aplicadas, entre eles os de administração, podem levar vantagem na proposição de novos negócios.

Quando a perspectiva não é de empreender, ainda assim a grande área de Ciências Sociais, Comércio e Direito leva vantagem sobre as demais, o que é explicativo de uma maior valorização maior ou menor de determinadas carreiras pela sociedade. Vieira e Marques (2014) mostram que a probabilidade de integração ao mercado de trabalho em Portugal, após a graduação, é maior entre os egressos dessas carreiras quando comparados com os egressos das humanidades, por exemplo. Outro estudo europeu com profissionais com até cinco anos de formação, realizado por Ramos, Parente e Santos (2014), mostra que as áreas de saúde, economia, administração e direito continuam valorizadas, enquanto as áreas de educação, artes e humanidade seguem com perda de importância.

A conclusão de um curso universitário, de toda sorte e independentemente da área, assegura uma condição de melhor inserção quanto à ocupação e às condições de trabalho (renda, horário de trabalho, outras vantagens etc.).

\section{PROCEDIMENTOS METODOLÓGICOS}

Este estudo classifica-se como descritivo quantitativo, mediante a realização de um Survey (levantamento), com o objetivo de obter dados empíricos (primários) a respeito dos estudantes universitários. A pesquisa quantitativa, segundo Moresi (2003, p. 64), é utilizada "quando se quer determinar o perfil de um grupo de pessoas, baseando-se em características que elas têm em comum", ou seja, esse estilo de pesquisa pode "criar modelos capazes de predizer se uma pessoa terá uma determinada opinião ou agirá de determinada forma, com base em características observáveis".

Para a realização da pesquisa de campo foi utilizado um questionário, que "consiste num elenco de questões que são apreciadas e submetidas a certo número de pessoas com o intuito de se obter respostas para a coleta de informações", sendo indicada a aplicação pessoalmente, pelo próprio pesquisador (FACCHIN, 2005, p. 147). O que incluir em um questionário é uma etapa importante, conforme Dencker (2007), tomando-se o cuidado para considerar nas perguntas os aspectos necessários para esclarecer o problema a ser pesquisado e evitando-se questões que, além de dispensáveis, podem ampliar o tempo de aplicação e cansar o respondente. 
A elaboração do questionário levou em consideração as características do público-alvo (estudantes de todas as séries do curso de administração de uma universidade pública do interior do Estado do Paraná, de oferta matutina e noturna), o local de aplicação (em sala de aula) e o tempo para preenchimento (até vinte minutos). Foi procurado elaborá-lo com um layout claro, com perguntas de fácil compreensão e respostas objetivas ou abertas, mas com espaço previamente definido para evitar divagações. Conforme Gunther e Lopes Júnior (2012), a pergunta fechada obriga o respondente a selecionar geralmente uma alternativa numa lista de opções predeterminadas, enquanto a pergunta aberta permite ao respondente a liberdade de expressar o que quiser sobre o assunto em pauta, ou seja, quando ambos os tipos de pergunta são utilizados na pesquisa, pode-se obter tanto respostas mais objetivas quanto mais reflexivas, quando for o caso. De acordo com Chagas (2000), quanto melhor e mais adequada for a apresentação, maior a probabilidade de se elevar o índice de respostas. O questionário totalizou quatorze questões, sendo que o Bloco I colhia dados sobre o "Perfil do estudante", com preenchimento objetivo e sem numeração, o Bloco II contemplava seis questões sobre os "Estudos" e o Bloco III abordava oito questões sobre o "Trabalho", conforme Quadro 1.

Quadro 1. Aspectos pesquisados com a aplicação do questionário aos estudantes de administração

\begin{tabular}{|l|l|}
\hline \multicolumn{1}{|c|}{ Bloco } & \multicolumn{1}{c|}{ Conteúdos pesquisados } \\
\hline $\begin{array}{l}\text { I - Perfil do } \\
\text { estudante }\end{array}$ & $\begin{array}{l}\text { Série e turno que estuda, Idade, Sexo, Cidade de residência, Raça/etnia, } \\
\text { Estado civil, Quantidade de pessoas no mesmo local de residência. }\end{array}$ \\
\hline II - Estudos & $\begin{array}{l}\text { Escola (pública ou privada) frequentada no ensino fundamental e na } \\
\text { educação básica, Se trabalhou durante o ensino médio, Se fez curso pré- } \\
\text { vestibular, Motivações para cursar administração, Percepção sobre } \\
\text { obtenção de emprego para estudantes de administração, Planos para o } \\
\text { futuro em termos educacionais. }\end{array}$ \\
\hline III - Trabalho & $\begin{array}{l}\text { Ocorrência e tipo de vínculo de trabalho, Ocorrência e valor de renda } \\
\text { com trabalho, Reflexos da experiência laboral sobre a vida acadêmica, } \\
\text { Dificuldades sentidas na busca de emprego, Se há desempregados no } \\
\text { núcleo familiar, Motivações para trabalhar e obter renda, Planos para o } \\
\text { futuro em termos profissionais. }\end{array}$ \\
\hline
\end{tabular}

Fonte. Questionário utilizado na coleta de dados da pesquisa.

A pesquisa de campo dividiu-se em três partes: elaboração e aplicação do questionário, organização e tabulação dos dados obtidos e análise e discussão. Cada etapa foi cuidadosamente realizada para que os objetivos traçados fossem obtidos, a saber: conhecer a realidade dos estudantes pesquisados quanto à sua situação atual e perspectivas de trabalho.

Os questionários foram aplicados durante o mês de novembro de dois mil e dezenove, totalizando cento e quarenta e cinco questionários respondidos por alunos do primeiro, segundo, terceiro e quarto anos, conforme Tabela 1. Antes da aplicação, todavia, passou por uma aplicação piloto com cinco alunos de uma das turmas e, ainda, depois disso, passou por uma validação com dois professores de Gestão de Pessoas (um com título de doutorado e outro com título de mestrado). Deve-se registrar, também, que os pesquisados assinaram um Termo de Consentimento Livre e Esclarecido, ficando cientes de que os resultados seriam utilizados exclusivamente para efeitos acadêmicos e sem a identificação dos informantes. 
Tabela 1. Número de estudantes pesquisados, por série e turno, em números absolutos e participação \% no total

\begin{tabular}{c|c|c|c|c|c|c|c|c}
\hline \multicolumn{4}{c|}{ MATUTINO $(40 \%)$} & \multicolumn{3}{c|}{ NOTURNO $(60 \%)$} & \multirow{2}{*}{ TOTAL } \\
\hline $1^{\circ}$ ano & $2^{\circ}$ ano & $3^{\circ}$ ano & $4^{\circ}$ ano & $1^{\circ}$ ano & $2^{\circ}$ ano & $3^{\circ}$ ano & $4^{\circ}$ ano & \\
\hline 14 & 14 & 14 & 16 & 18 & 23 & 20 & 26 & 145 \\
$(9,7 \%)$ & $(9,7 \%)$ & $(9,7 \%)$ & $(11,1 \%)$ & $(12,4 \%)$ & $(15,9 \%)$ & $(13,8 \%)$ & $(17,9 \%)$ & $(100 \%)$ \\
\hline
\end{tabular}

Fonte. Dados da pesquisa.

Como as matrículas ocorrem por disciplina e não por turno, não foi possível identificar exatamente o número de matriculados por série, mas a Secretaria do Curso estimou em 260 o número de alunos nos dois turnos pesquisados, revelando que a pesquisa abordou aproximadamente $56 \%$ dos matriculados.

Para facilitar a análise e interpretação, os dados foram organizados em Planilha do Microsoft Office Excel, o que facilitou a compilação específica por estudante e a totalização por respostas obtidas. A análise foi enriquecida com a geração de gráficos e tabelas e as questões do questionário foram tabuladas, inclusive as questões abertas, mediante a criação de categorias específicas de respostas. As questões fechadas, como as referentes à categorização do estudante ou que apresentavam respostas préelaboradas, foram naturalmente tabuladas estatisticamente de acordo com as respostas assinaladas/informadas. Já para a categorização das questões abertas, pelas características da pesquisa e do questionário, foram observados os seguintes passos sugeridos por Bardin (2011): pré-análise das respostas, exploração do material obtido e tratamento dos resultados e interpretação. No caso da pergunta sobre a "razão de ter optado pelo curso de administração", foram inicialmente listadas todas as respostas e na sequência agregadas as respostas similares a partir de termos ou conceitos-chave, da maior para a menor ocorrência, conforme se verá na análise e discussão dos resultados. Resta esclarecer que, quanto à natureza da análise de conteúdo das respostas abertas, o próprio trabalho de sistematização e organização dessas categorias já as torna quantificáveis, resultando numa apresentação quantitativa dos dados, conforme defende Lasswell (1982).

Depois de cumpridas as etapas de pesquisa bibliográfica e de pesquisa de campo com os estudantes, foi possível analisar e discutir os resultados, cumprindo-se os objetivos inicialmente traçados e contribuindo para a geração de subsídios para a compreensão da inserção profissional dos estudantes de administração, conforme apresentado a seguir.

\section{ANÁLISE E DISCUSSÃO DOS RESULTADOS}

- Bloco I - Perfil do estudante

$\mathrm{Na}$ análise que permitiu a caracterização dos estudantes de administração pesquisados, descobriu-se que, embora pequena, há maior participação masculina $(52,86 \%)$ do que feminina $(47,14 \%)$, o que difere de outras carreiras, em que a prevalência é bastante maior masculina (engenharias) ou feminina (licenciaturas). 
Assim, os dados trazem uma perspectiva de maiores oportunidades de carreiras também para as mulheres, possivelmente pela variedade de campos de atuação proporcionadas pelo curso de administração. Apesar disso, conforme Closs e Rocha-de-Oliveira (2015, p. 535) "para as mulheres, questões de gênero podem se impor como limites nas suas trajetórias profissionais", pois apesar de se perceber iguais condições nas salas de aula, no mercado de trabalho dificilmente isso ocorre.

Os estudos de Siqueira, Miranda e Cappele (2019) mostram que o próprio público feminino, pelas condições em que se encontra na sociedade e tendo em vista a construção social a seu respeito, nem sempre percebe as desigualdades de gênero de que é vítima. Nas últimas décadas, é fato que as mulheres passaram a desempenhar papéis diferentes dos tradicionalmente a elas reservados pela sociedade, ocupando inclusive cargos de liderança no mercado de trabalho e protagonizando ações importantes ocupando postos indispensáveis em momentos de crise como no caso da pandemia da COVID-19 (SILVA, 2020), mas de acordo com Biasoli (2016), isso ainda não é suficiente para retirá-las da condição de marginalização em relação aos homens, o que se reflete sobre aspectos que impactam na sua segurança, saúde e qualidade de vida. $\mathrm{O}$ estudo de Proni e Proni (2018) é esclarecedor ao mostrar que as mulheres continuam sendo discriminadas nos processos seletivos para ocupação de cargos mais elevados, sendo ainda comum encontrar situações em que elas recebem remuneração menor, mesmo quando ocupam funções iguais às dos homens.

Ao analisar a idade dos respondentes observa-se que os que tem até 21 anos, idade considerada adequada para o curso quando se observa o fluxo natural de avanço do ensino médio para a universidade, representam $60 \%$ do total. Logo, os outros $40 \%$ estão acima dessa faixa etária. Segundo o Estatuto da Juventude (BRASIL, 2013), é considerado jovem o indivíduo com idade de até 29 anos. Assim, dessa parcela de estudantes com mais de 21 anos, 34,48\% (50) dos respondentes têm de 22 a 29 anos e $5,52 \%$ têm 30 anos ou mais. Quanto menos jovem for o estudante, entende-se que maior é a pressão social para obter trabalho e renda. Ademais, segundo Rueda, Martins e Campos (2004, p. 64),

Considerando que, nesta época de mudanças, as empresas estão procurando alternativas de modernização de seus sistemas e processos produtivos e passando por constantes diminuições em seu quadro de pessoal, a condição de ser empregável passa a ser mais importante do que o emprego, exigindo que as pessoas tenham maior capacidade de aprender e de se adaptar à nova realidade de mercado. Com a redução dos postos de trabalho, começa a surgir uma nova proposta na qual as pessoas não procuram mais um emprego tradicional, mas sim trabalho, passando a oferecer soluções para os diversos problemas que as empresas e a própria sociedade possam enfrentar.

Essa demanda organizacional por profissionais que tenham condições técnicas e atitudes adequadas para oferecer soluções para os problemas sociais e organizacionais, conforme mencionado pelos autores, põe os jovens universitários em evidência, tendo em vista o perfil etário e a relativa vantagem de escolarização que apresentam. Há casos em que a falta de experiência pode até pesar favoravelmente em relação ao objetivo de moldar os novos trabalhadores, proporcionando mais liberdade no momento de encontrar soluções para os problemas do trabalho, uma vez que os mais jovens veem na organização oportunidades de "aprendizado", de complementação da "escola" e melhoria da "bagagem" profissional (OLIVEIRA; HONÓRIO, 2014). Ainda assim, a 
busca do curso por pessoas menos jovens indica que precisam apresentar-se ao mercado em condições pelo menos comparáveis aos mais jovens, ou seja, com uma escolaridade que lhes dê alguma chance nos processos seletivos.

Quando se pesquisa o público universitário, é natural esperar que a maioria seja solteira. Chama a atenção o fato de se ter encontrado outras configurações (pelo menos 16 casados e 6 que não identificaram sua qualificação civil), o que representa 11,03\% do total. Isso pode implicar, somado à idade mais elevada, ainda maior pressão para a inserção ocupacional e obtenção de renda, pois se já é difícil enfrentar as obrigações sendo solteiro, tendo uma família isso se torna ainda mais desafiador.

Uma informação importante para analisar a situação e as condições de estudo dos universitários é a questão da moradia. Pela característica da instituição pesquisada, que oferta o curso de administração nos turnos matutino e noturno, e que está localizada numa cidade-polo, é relevante a informação de que recebe estudantes oriundos de outros municípios. Assim, os dados revelam que $91,8 \%$ dos respondentes residem na cidadesede, enquanto os outros $8,2 \%$ residem em outras cidades do entorno, o que os coloca, em muitos casos, em uma situação de sobrecarga de atividades, a saber: tempo de estudos, tempo de trabalho, tempo de deslocamento entre a casa, o local de trabalho e o local de estudos. Nesse último caso, considerando a sua região de abrangência, há estudantes que residem a mais de cem quilômetros de distância da universidade, dando uma ideia do tempo que se gasta nesse deslocamento e a sobrecarga a que estão expostos, em especial se conciliam estudo e trabalho. Mas independentemente da distância, a perda de um tempo valioso no trajeto entre casa-trabalho-escola coloca os estudantes numa situação de grande desvantagem em relação aos colegas que não precisam trabalhar. De acordo com Vargas e Paula (2013), o prejuízo acadêmico é considerável, gerando uma categoria de estudantes excluídos ou deserdados no interior da própria universidade.

\section{- Bloco II - Estudos}

Verificou-se que a parcela dos que frequentaram escola pública na educação básica foi de $80,0 \%$, no caso do ensino fundamental, e de 75,9\%, no caso do ensino médio, ou seja, a grande maioria dos estudantes pesquisados são oriundos da educação básica pública. Além disso, da totalidade dos respondentes, 73,1\% entraram na universidade sem ter feito preparação adicional através de cursinho pré-vestibular, o que é positivo quando se considera que esse curso apresenta uma grande procura, exigindo uma boa preparação para aprovação no processo seletivo.

Os dados mostram que quase metade do total de estudantes $(47,6 \%)$ tiveram sua primeira experiência de trabalho já durante o ensino médio. Considerando-se a sua situação de estudante universitário, nada menos do que 93,8\% declarou já ter desenvolvido alguma atividade laboral remunerada, seja através de estágio, emprego formal ou informal, contrato de aprendizagem ou atuação como freelancer. Associando essa informação com os dados econômicos, pode-se deduzir que os estudantes buscam precocemente o trabalho em função da necessidade de renda, mas também para assegurar um espaço no mercado de trabalho cada vez mais concorrido, além de se esforçar para dar continuidade aos estudos. De acordo com Bernardim (2013, p. 205):

Os estudantes de Ensino Médio buscam realizar na escola as necessidades mais imediatas, como a formação profissional e a convivência com os colegas, além de potencializar a satisfação de 
outros desejos, como a obtenção de emprego e o prosseguimento dos estudos. Essa última expectativa, portanto, recoloca o ensino médio como uma etapa importante da formação, mas não necessariamente a última. Só o prosseguimento nos estudos, em nível superior, parece satisfazer as necessidades mais amplas do indivíduo no século XXI, pelo menos para grande parte dos alunos.

A decisão de continuar estudando está bastante condicionada à possibilidade de obtenção de emprego e renda ainda durante o curso ou logo depois de tê-lo concluído. Nota-se que a quase totalidade dos respondentes concordam que o curso trará boas oportunidades de emprego, pois $98,6 \%$ deles acreditam nessa relação entre o curso e as vagas de trabalho. Uma parcela de $54,4 \%$ afirmou que a abrangência do curso é sua melhor vantagem no mercado.

A formação do nível superior está atrelada, segundo estudos de Martins e Machado (2018), às características individuais (como sexo e idade) e condições socioeconômicas, tais como rendimento no início de carreira, concorrência, duração do curso e perspectivas de estar empregado.

As motivações para cursar administração mais apontadas pelos universitários que participaram desta pesquisa foram as perspectivas de boas oportunidades no mercado de trabalho $(39,3 \%)$ e ao fato de gostar da área $(35,2 \%)$. Quanto a essa pretensão de se inserir como empregado e, portanto, assalariado, Dias (2009, p. 56) esclarece:

A condição de assalariado e a promoção do acesso ao trabalho introduzem uma questão contraditória, uma vez que, ao mesmo tempo em que libertam o sujeito, aprisionam-no à tutela contratual. Esta condição encerra em si mecanismos de inclusão e exclusão nos quais o trabalhador está constantemente subordinado a uma economia capitalista excludente.

Apesar de um emprego acenar como uma possibilidade de autonomia dos jovens-estudantes em relação à família, por exemplo, o mesmo também aprisiona com contratos, leis e normas a serem observados. Porém, se o sistema é regido por essas normas, é inevitável ingressar nesse mercado, seja antes, durante ou após a graduação. Além de tudo, os vínculos formais criados pelo emprego, ainda que não sejam os melhores, são preferíveis aos empregos sem vínculo, que não asseguram aos trabalhadores garantias e direitos estabelecidos na legislação trabalhista e previdenciária.

Quando se trata das expectativas dos entrevistados quanto ao futuro educacional, a pesquisa revelou que a maioria pretende continuar os estudos, conforme o Gráfico 1.

Gráfico 1. Expectativas dos estudantes de administração quanto ao futuro educacional (em \% do Total) 


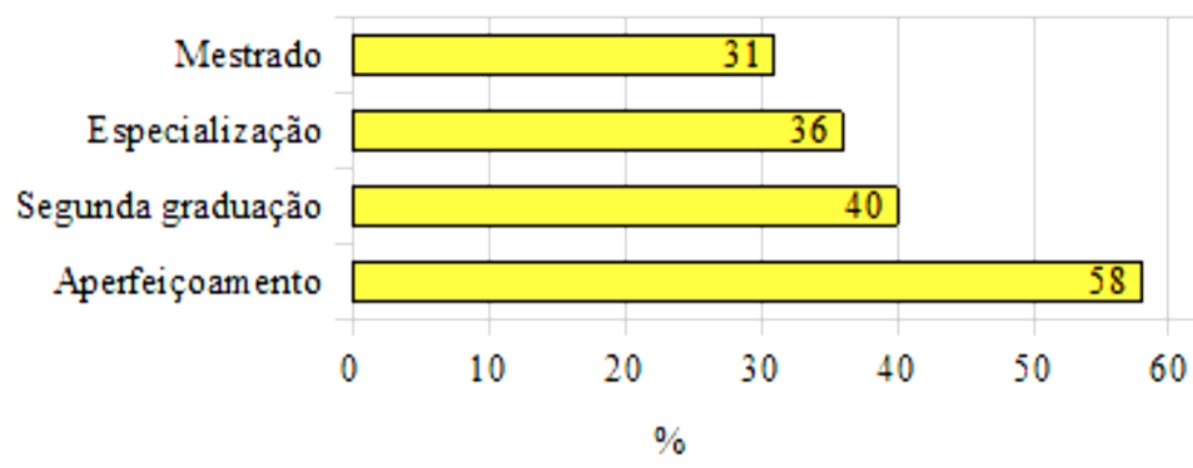

Fonte. Dados da pesquisa. Nota. Questão que aceitava múltiplas respostas

O que se percebe é o interesse de continuar estudando como forma de se manter em condições de obter uma boa inserção no mercado de trabalho. Quanto a uma segunda graduação, o estudo de Chiocca, Favretto e Favretto (2016) mostra que, além de não ser incomum, há inúmeras justificativas para isso nos dias de hoje, desde a insatisfação com a primeira graduação, passando pela complementação de conhecimentos e envolvendo até a busca da autorrealização, quando isso é possível.

O Gráfico 1 mostra que o interesse de realização de estudos de pós-graduação lato ou stricto sensu aparecem com 36 e $40 \%$, perdendo para cursos de aperfeiçoamento e uma segunda graduação, com 58 e $40 \%$, respectivamente. Sabe-se que a busca por qualificação profissional se incorporou definitivamente na vida das pessoas nas últimas décadas, o que justifica o interesse pelo aperfeiçoamento e especialização. $O$ que aparece como novidade, porém, é o desejo de buscar formação ou especialização em áreas diferentes da formação original, o que justifica a permanência ou retorno das pessoas à universidade com o interesse de cursar uma segunda graduação. Moura e Menezes (2004) alertam que o processo de escolha de um curso não é simples, requerendo uma tomada de decisão para a qual nem sempre as pessoas estão preparadas, tendo em vista a falta de suporte familiar ou mesmo das instâncias educacionais anteriores. Nesse sentido, por ocasião da escolha de uma nova graduação, é de se esperar que o interessado tenha amadurecido enquanto estudante, durante o tempo em que frequentou o primeiro curso, e enquanto profissional, com alguma experiência de trabalho acumulada no período, assegurando condições de maior assertividade em relação a essa segunda escolha, pois o que está em jogo é o seu presente e futuro profissional.

No estudo ora relatado, o desejo de uma nova graduação pode estar sinalizando que o curso de administração foi escolhido por apresentar uma formação mais genérica com boas perspectivas de ingresso no mercado. Uma vez isso assegurado, a busca de outra graduação representaria o retorno aos interesses mais subjetivos dos respondentes, ou mesmo uma forma de potencializar a formação e a inserção profissional mais robusta, conciliando dois cursos que podem se complementar, em especial quando as carreiras citadas como de preferência pelos respondentes foram: contabilidade, direito, economia e psicologia.

- Bloco III - Trabalho

Entre os estudantes pesquisados, 30,3\% trabalham entre 31 e 40 horas semanais e $29,6 \%$ entre 21 e 30 horas semanais, notando-se que boa parte do seu tempo é 
consumida pelo trabalho ou estágio remunerado. Se forem considerados os dois grupos, então constata-se que praticamente $60 \%$ dos estudantes têm alguma atividade laboral com carga horária igual ou superior a quatro horas diárias, o que implica em um esforço, quanto maior for a carga-horária de trabalho e a necessidade de deslocamento, para conciliar as atividades de estudo e trabalho.

Esses dados revelam que há relações positivas e negativas entre as experiências simultâneas de trabalhar e estudar. Para 48,3\% dos estudantes o maior ganho é o conhecimento prático ou a experiência que a atividade de trabalho proporciona, enriquecendo ou permitindo a operacionalização dos conhecimentos teóricos obtidos nas aulas. Apesar dessa positividade, há aspectos negativos que não podem ser desconsiderados: o primeiro deles é a declaração de 27,6\% de que essa dupla função, de estudante e trabalhador, acarreta sobrecarga, comprometendo a semana toda com atividades de trabalho e estudo, sem disponibilidade de tempo para outras necessidades igualmente importantes, em especial de lazer e de sociabilidade; além disso, para 26,2\% dos respondentes o cansaço é outro fator a ser considerado, o que se agrava pela falta de tempo para atividades de descanso durante a semana. Ainda recorrendo a Oliveira, Piccinini e Silveira (2010, p. 179), verifica-se que

O trabalho adquire múltiplos significados ao longo do tempo, quando tais significados foram positivos, como meio de realização pessoal e formação de identidades; quando negativos, como algo pesado e degradante ou explorador e contribuindo para a desigualdade dos indivíduos. Considerando que estamos em um período de expressivas transformações no universo de trabalho, acredita-se que ele pode estar adquirindo novos significados ou reforçando antigas representações.

Há outros estudos que apontam para uma possível ressignificação do trabalho na sociedade contemporânea. Quando os estudantes tomam consciência de que se encontram em desvantagem frente a seus colegas que não precisam conciliar tempo de trabalho com tempo de estudo ou que não dependem de renda própria enquanto são estudantes, isso pode ter reflexos sobre a relação que estabelecem com a escola ou com o próprio trabalho. Nos estudos que fez sobre a relação entre juventude e trabalho, Ribeiro (2011) constata que, em termos socioculturais, há hoje uma "descronologização" do percurso etário, uma desconexão dos atributos tradicionais de maturidade, uma vivência de papéis tradicionalmente adultos (trabalho, família, finanças) ainda na juventude, o que favorece trajetórias singulares determinadas pela incerteza e imprevisibilidade. Já para Ribeiro e Léda (2004, p. 81), "o trabalho precisa estar integrado à vida, ter um sentido, não pode se restringir a ser um meio de sobrevivência. $O$ indivíduo precisa vislumbrar a possibilidade de realização dos seus planos e projetos, desvinculados do mero acesso a bens materiais e suas simbologias". Assim, a necessidade de trabalhar não pode superar o valor intrínseco que do trabalho na vida das pessoas, devendo haver um esforço social coletivo para que as pessoas possam estudar sem enfrentar o dilema cruel de escolher entre "estudo ou trabalho".

Os pesquisados declararam encontrar dificuldade para conseguir emprego. Cerca de 49,6\% deles afirmaram que a falta de experiência é o maior empecilho para conseguir um trabalho, e 26,9\% afirmaram não haver oportunidades suficientes para todos que procuram vagas. Isso demonstra que apesar da escolarização de nível superior, as dificuldades com o desemprego ainda são muitas. Mas o fato de 93,8\% deles já ter tido alguma experiência com atividades remuneradas, conforme apresentado 
anteriormente, já é uma vantagem sobre os concorrentes no momento da seleção. Segundo Dias (2009, p. 63):

Escolher uma trajetória após o período universitário pode se transformar em um suplício, pois existem múltiplas alternativas: o caminho do estágio, a busca de outra especialização e até o início das atividades profissionais. Porém, estas podem ou não serem percebidas como opções de sucesso. A busca do primeiro emprego se configura como um momento particular, objetivamente gerador de inseguranças e ansiedades para o sujeito. Outra condição é a urgência da tomada decisão, na qual o fator complicador é a falta de tempo para realizar a escolha.

Outro aspecto a ser considerado é que muitos estudantes não se sentem preparados psicologicamente para ingressar no mercado formal de trabalho. As primeiras impressões, causadas pelas entrevistas de emprego, são muito importantes e, sem um preparo e auxílio adequado, essa experiência pode causar traumas e frustrações que poderiam ser evitados.

Quando se trata das expectativas dos entrevistados em relação ao futuro profissional, a pesquisa revelou que já estão sob análise uma série de opções, desde que se consiga obter trabalho e renda de qualidade, conforme o Gráfico 2.

Gráfico 2. Expectativas dos estudantes de administração quanto ao futuro profissional (Foco em $\%$ do Total)

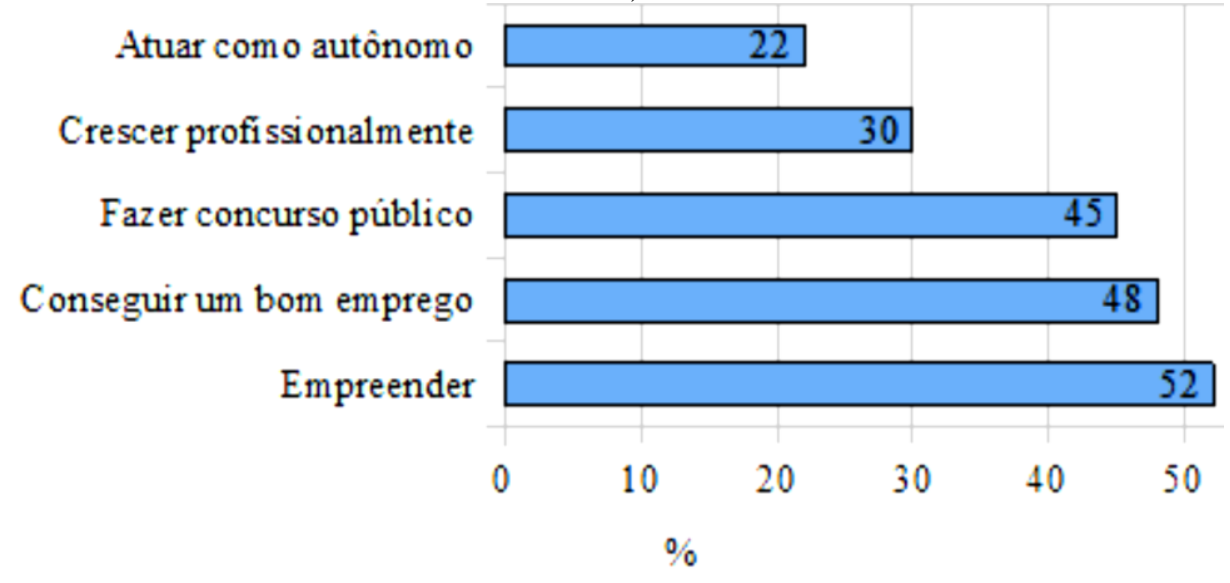

Fonte. Dados da pesquisa. Nota. Questão que aceitava múltiplas respostas

Criar um pequeno negócio, disputar um espaço no concorrido serviço público, obter um bom emprego ou avançar na carreira em que já está são as opções consideradas pelos estudantes que se caracterizam como trabalhadores. De acordo com Oliveira, Detomini e Melo-Silva (2013, p. 512), "os formandos têm expectativas de que uma transição bem-sucedida seja aquela na qual poderão encontrar um emprego na sua área de formação, de preferência sendo aprovados em concurso público, ou que consigam continuar seus estudos, fazendo pós-graduação”.

Nesta fase da pesquisa não estava previsto o aprofundamento das respostas obtidas com o questionário, mas algumas manifestações espontâneas dos estudantes chamam a atenção sobre alternativas de carreira. Alguns declararam que já atuam ou que pretendem atuar como Microempreendedores Individuais- MEI. Essa modalidade foi instituída pela Lei Complementar n. 128, de 19 de dezembro de 2008 (BRASIL, 
2008), tendo como um dos objetivos a simplificação do processo de formalização e legalização de pequenos negócios individuais no território nacional. Tanto pela facilidade e barateamento dessa legalização quanto pela alternativa ao desemprego e desamparo social e trabalhista, essa política tem dado resultados, uma vez que já são mais de 10 milhões de trabalhadores atuando como microempreendedores no Brasil, engrossando o número de trabalhadores que se encaminham para o "empreendedorismo por necessidade" (G1 ECONOMIA, 2020).

Outro achado importante, embora seja residual no conjunto dos estudantes pesquisados, foi o desejo manifestado de dedicar-se aos estudos na área de administração, desenvolver a competência em uma língua estrangeira e buscar uma forma de inserção internacional, seja através de intercâmbio ou participação em programas de internacionalização dentro da própria universidade, seja mediante iniciativa individual de colocação no exterior. Essa última opção converge com as necessidades específicas de determinados países, dada a impossibilidade de suprimento de vagas com trabalhadores nativos, muito comum no Japão (NIPPON.COM, 2018), ou mesmo a dificuldade de preenchimento de determinados postos mais especializados em algumas regiões do país, verificada no Canadá (ABRACOMEX, 2020).

Assim, os estudantes alimentam grandes expectativas quanto ao seu futuro profissional, o que é esperado e natural nessa fase da vida. O problema é que somente alguns atingem suas metas com facilidade, restando à maioria muito esforço e determinação para alcançar esse objetivo. Independentemente disso, todos precisam dar mostras de empenho durante sua carreira escolar, submetendo-se a um longo período de preparação que favoreça sua inserção profissional qualificada, que assegure renda e alguma satisfação pessoal. Isso é o que move os universitários na sua transição, nem sempre tranquila, da condição de estudante e de estudante-trabalhador até chegar à condição de profissional inserido e realizado.

\section{CONSIDERAÇÕES FINAIS}

Este estudo analisou a inserção profissional dos estudantes do curso de administração de uma universidade pública paranaense, sendo possível identificar que uma grande parcela deles já teve experiências de trabalho tanto na educação básica quanto no ensino superior, em especial nesse último caso, quando são maiores as chances de estágio remunerado e de envolvimento com projetos desenvolvidos no ambiente acadêmico. Os estudantes percebem que tais experiências são próprias da transição "vida estudantil" para a "vida profissional", através de estágios, envolvimento como bolsistas em pesquisas ou atividades de extensão, contratos de aprendizagem, atividades informais ou mesmo nos negócios da família.

Para uma parte dos estudantes as rápidas e não continuadas oportunidades de trabalho (iniciação científica de um ano, estágio de seis meses etc.) representam uma transição lenta, não determinantes quanto à renda, mas importantes para o processo de formação e construção do currículo. Para os demais, que apresentam alta necessidade de renda para si ou para a família, nesse caso principalmente os estudantes do noturno, essas experiências (que apresentam-se com menor diversidade de opções, tendo em vista a dependência financeira) revelam que a atividade laboral simultânea ao curso torna-se não somente uma iniciação para a posterior inserção profissional mais robusta; pelo contrário, ganham contornos de "emprego", ainda que não tenham as mesmas garantias e direitos. 
Apesar disso, embora a inserção precoce no mundo do trabalho possa expor os estudantes a uma sobrecarga de atividades, por outro lado também proporciona experiências positivas para pleitearem o ingresso em empresas maiores e/ou que podem oferecer melhores salários e vantagens.

Aqueles que se ressentem dessas oportunidades de iniciação à vida profissional sabem que irão encontrar maior dificuldade depois de concluída a formação. Ainda assim, seguem alimentando a expectativa de buscar colocação em grandes empresas, de obter aprovação em concursos públicos ou de trabalhar no exterior. Enquanto isso não ocorre, incorporam a necessidade/possibilidade de continuarem os estudos, cursando especialização ou mestrado, e de obterem alguma experiência e salvaguarda financeira na condição de microempreendedores individuais.

Os instrumentos utilizados e os objetivos perseguidos não permitem afirmações conclusivas sobre o processo de planejamento de carreira dos estudantes, mas o percurso e as análises feitas durante a pesquisa permitem lançar a hipótese de que os estudantes universitários do curso pesquisado, salvo exceções, apresentam um certo conformismo com a realidade do mercado e com as possibilidades de carreira, o que é convergente com as descobertas de Ribeiro (2011). Assim, as manifestações sobre os próximos passos estão amparados no status quo vigente de tentar um bom emprego numa grande companhia ou passar em concurso público. Se isso não for possível, contentam-se com as demais possibilidades de emprego ou mesmo de empreender algum negócio como alternativa para a obtenção de renda.

Tais circunstâncias reforçam a tese de que os jovens e adultos que confrontam-se diariamente com a realidade de ter que estudar e trabalhar vão construindo seu percurso equilibrando-se entre as possibilidades de inclusão universitária e profissional, que nem sempre satisfazem suas necessidades ou aspirações mais imediatas, e os riscos de exclusão, conforme já antecipava Castel (1995). Tal marginalização pode se dar pela falta de oportunidade de trabalho, pela impossibilidade de conciliar trabalho e estudo ou mesmo pela vulnerabilidade socioeconômica decorrente dessas situações.

A pesquisa permitiu compreender as dificuldades e oportunidades com as quais os estudantes se deparam para conseguir sua inserção laboral. Embora haja estudos tratando da transição dos estudantes da universidade para o trabalho, a exemplo daqueles apontados neste artigo, trata-se de um tema relevante e dinâmico que apresenta lacunas a serem continuamente perseguidas, como: qual a contribuição da escola/universidade para o esforço de aproximação entre o mercado de trabalho e os seus alunos/egressos? Há muitas diferenças nas carreiras abraçadas e nas dificuldades de inserção profissional vivenciadas pelos universitários que podem ser explicadas a partir de um recorte de gênero? Que aspectos formativos ou curriculares diferenciam os estudantes que se inserem mais facilmente no mercado de trabalho dos demais? Qual a relação existente entre a permanência por mais tempo na universidade (especialização, mestrado) e as condições de trabalho e renda? São todas questões pertinentes que se somam para a melhor compreensão da temática.

Especificamente em relação à metodologia que proporcionou os dados e resultados apresentados nesta pesquisa, uma limitação do estudo foi a utilização exclusiva de questionário para a coleta de informações. Talvez a realização de entrevistas com os respondentes de alguns questionários selecionados poderia complementar as informações obtidas. A escolha exclusiva de estudantes do curso de administração para a pesquisa empírica foi valiosa, tendo em vista as oportunidades da 
carreira e a abrangência que o curso oferece para a formação, mas em outras investigações seria recomendável abordar um número maior de cursos e de estudantes. Outra possibilidade para o prosseguimento do estudo seria a realização de uma pesquisa do tipo longitudinal de trajetórias estudantis e profissionais, o que permitiria aprofundamento dos achados e amplitude do período de alcance dos dados obtidos.

Por fim, os resultados indicam a necessidade de que as coordenações de curso conheçam melhor seu alunado, assim como suas condições socioeconômicas e intenções profissionais e de continuidade dos estudos. Tal aproximação pode favorecer o estreitamento das relações com os estudantes, tanto no âmbito didático-pedagógico quanto no encaminhamento profissional.

\section{REFERÊNCIAS}

ABRACOMEX - Associação Brasileira de Consultoria e Assessoria em Comércio Exterior. Quais são os países que mais contratam brasileiros. Vitória, ES: 03 abr. 2020. Disponível em: https://www.abracomex.org/quais-sao-os-paises-que-mais-contratambrasileiros. Acesso em: 20 abr. 2021.

ALMEIDA, Patrícia A.; TARTUCE, Gisela L. B. P.; NUNES, Marina M. R. Quais as razões para a baixa atratividade da docência por alunos do Ensino Médio? Psicol. Ensino \& Form., Brasília, v. 5, n. 2, p. 103-121, 2014. Disponível em: http://pepsic.bvsalud.org/scielo.php?script=sci_arttext\&pid=S2177-

20612014000200007\&lng=pt\&nrm=iso. Acesso em: 15 mar. 2021.

BARDAGI, Marucia P.; HUTZ, Claudio S. Mercado de trabalho, desempenho acadêmico e o impacto sobre a satisfação universitária. Revista de Ciências Humanas, Florianópolis, V. 46, N. 1, p. 183-198. Disponível em: https://periodicos.ufsc.br/index.php/revistacfh/article/view/21784582.2012v46n1p183/23110. Acesso em: 06 mai. 2020.

BARDIN, L. Análise de conteúdo. São Paulo: Edições 70, 2011.

BERNARDIM, Márcio Luiz. Educação e trabalho na perspectiva de egressos do ensino médio e estudantes universitários. Nuances: estudos sobre Educação. São Paulo: Ano XIX, n. 25, v. 01, p. 200-217, jan./abr. 2013. Disponível em: https://unicentro.academia.edu/M\%C3\%A1rcioLuizBernardim. Acesso em: 10 jul. 2020.

BIASOLI, Patrícia K. Mulheres em cargos de gestão: dificuldades vinculadas ao gênero. Revista Indicadores Econômicos FEE, v. 43, n. 3, p. 125-140, 2016. Disponível

em: https://revistas.dee.spgg.rs.gov.br/index.php/indicadores/article/view/3672. Acesso em: 27 mar. 2021.

BRASIL. Estatuto da Juventude. Brasília: Lei N. 12.852, de 5 de agosto de 2013. Presidência da República, 2013. Disponível em: http://www.planalto.gov.br/ccivil_03/_Ato2011-2014/2013/Lei/L12852.htm. Acesso em: 8 jul. 2020.

BRASIL. Presidência da República. Casa Civil. Lei Complementar n. 128, de 19 de dezembro de 2008. Altera a Lei Complementar no 123, de 14 de dezembro de 2006, altera as Leis nos 8.212, de 24 de julho de 1991, 8.213, de 24 de julho de 1991, 10.406, de 10 de janeiro de 2002 - Código Civil, 8.029, de 12 de abril de 1990, e dá outras 
providências. Brasília, DF: Diário Oficial da União, 22 dez. 2008. Disponível em: http://www.planalto.gov.br/ccivil_03/Leis/LCP/Lcp128.htm. Acesso em: 20 mar. 2021.

CASTEL, R. De la exclusión como estado a la vulnerabilidad como proceso. Arquipiélago, Barcelona, n. 21, 1995.

CHAGAS, Anivaldo T. R. O Questionário na Pesquisa Científica. São Paulo: USP, 2000.

CHAVES, Miguel; RAMOS, Madalena; SANTOS, Rui. Convergences and disparities of work orientations among recent graduates in Portugal. Sociologia, Problemas e Práticas, Lisboa, n. 80, p. 9-29, 2016. Disponível em: https://journals.openedition.org/spp/2042. Acesso em: 16 mar. 2021.

CHIOCCA, Bruna; FAVRETTO, Liani H.; FAVRETTO, Jacir. Escolha profissional: fatores que levam a cursar uma segunda graduação. ReCaPe Revista de Carreiras e Pessoas. São Paulo. v. vi, n. 1, Jan/Fev/Mar/Abr 2016. Disponível em: https://core.ac.uk/download/pdf/205114417.pdf. Acesso em: 05 nov. 2020.

CLOSS, L. Q., ROCHA-DE-OLIVEIRA, S. História de Vida e Trajetórias Profissionais: Estudo com Executivos Brasileiros. RAC, Rio de Janeiro, v. 19, n. 4, art. 6, pp. 525-543, Jul./Ago. 2015. Disponível em: http://dx.doi.org/10.1590/19827849rac20151951. Acesso em: 14 jul. 2020.

CORTEZ, Pedro A.; DA SILVA VEIGA, Heila M. Intenção empreendedora na universidade. Cienc. Psicol., Montevideo, v. 13, n. 1, p. 134-149, jun. 2019. Disponível em: $\quad$ http://www.scielo.edu.uy/scielo.php?script=sci_arttext\&pid=S168842212019000100134\&lng=es\&nrm=iso. Acesso em: 13 abr. 2020.

DENCKER, Ada F. M. Métodos e técnicas de pesquisa em turismo: planejamento, métodos e técnicas. São Paulo: Futura, 2007.

DIAS, Maria S. L. Sentidos do trabalho e sua relação com o projeto de vida de universitários. Programa de Pós-Graduação em Psicologia - Tese. Universidade Federal de Santa Catarina. Florianópolis, 2009. 270 fl. Disponível em: https://repositorio.ufsc.br/bitstream/handle/123456789/106654/265561.pdf?sequence $=1$ \&isAllowed=y. Acesso em: 5 mai. 2020.

DIAS, Maria S. L.; SOARES, Dulce H. P. A escolha profissional no direcionamento da carreira dos universitários. Psicol. cienc. prof., Brasília, v. 32, n. 2, p. 272-283, 2012. Disponível em: $\quad$ http://www.scielo.br/scielo.php?script=sci_arttext\&pid=S141498932012000200002\&lng=pt\&nrm=iso. Acesso em: 14 jul. 2020.

FACCHIN, Odília. Fundamentos de metodologia. 4. ed. São Paulo: Saraiva, 2005.

FERREIRA, André; ABRANCHES, Caroline S. Desempenho acadêmico versus renda: análise comparativa realizada com egressos de um curso de administração. Revista GUAL, Florianópolis, v. 11, n. 3, p. 01-19, setembro, 2018. Disponível em: https://periodicos.ufsc.br/index.php/gual/article/view/1983-4535.2018v11n3p01.

Acesso em: 21 jan. 2021.

FERREIRA FILHO, Edson P.; ANDRADE, Aline F.; SOUZA, Luciano Q. Contemporaneidade: a percepção dos acadêmicos do curso de administração quanto ao desenvolvimento de sua Empregabilidade. X Simpósio de Excelência em Gestão e 
Tecnologia, SEGeT. Resende, RJ: AEDB, Out. 2013. Disponível em: https://www.aedb.br/seget/arquivos/artigos13/43318478.pdf. Acesso em: 7 jan. 2021.

FERREIRA, Juliana D.; KUHN, Nuvea; KAIBER, Natieli P.; ALVES, Flávia L. Inserção profissional no mundo do trabalho: perspectiva de egressos e formandos do curso de administração. Revista Foco, v. 12, n. 1, p. 158-179, nov./fev. 2019. Disponível em file:///D:/Users/Meu\%20Not/Downloads/Insercao_profissional_no_mundo_do_trabalho _perspec.pdf. Acesso em: 20 mar. 2021.

FONTANINI, Carlos A. C.; WOLLMANN, Dewey M.; CHIESA, Amanda M. Fatores contribuintes para o aprendizado dos estudantes de administração de uma escola de negócios. Ensaios pedagógicos UFSCAR, v. 3, n. 3, 2019. Disponível em: http://www.ensaiospedagogicos.ufscar.br/index.php/ENP/article/view/161/0. Acesso em: 15 mar. 2021.

GUNTHER, H.; LOPES JÚNIOR, J. Perguntas Abertas Versus Perguntas Fechadas: Uma Comparação Empírica. Psicologia: Teoria e Pesquisa, v. 6, n. 2, p. 203-213, 15 ago. $2012 . \quad$ Disponível em: https://periodicos.unb.br/index.php/revistaptp/article/view/17094. Acesso em: 2 jun. 2020.

G1 ECONOMIA. Número de MEIs no país ultrapassa a marca de 10 milhões de brasileiros. $\quad 27 \quad$ abr. $2020 . \quad$ Disponível em: https://g1.globo.com/economia/noticia/2020/04/27/numero-de-meis-no-pais-ultrapassaa-marca-de-10-milhoes.ghtml. Acesso em: 20 mar. 2021.

JACOB, Marita, WEISS, Felix. From higher education to work patterns of labor market entry in Germany and the US. High Educ. v. 60, 529-542, 2010. Disponível em: https://doi.org/10.1007/s10734-010-9313-y. Acesso em: 22 mar. 2021.

LASSWELL, Harold. Por que ser quantitativista? In: LASSWELL, H; KAPLAN, A. (org.) A linguagem da política. Brasília. Brasília, DF: Editora da Universidade de Brasília, 1982.

MAGALHAES, Mauro O. Sucesso e fracasso na integração do estudante à universidade: um estudo comparativo. Rev. bras. orientac. prof., São Paulo, v. 14, n. 2, p. 215-226, dez.2013. Disponível em: http://pepsic.bvsalud.org/scielo.php?script=sci_arttext\&pid=S16793902013000200007\&lng=pt\&nrm=iso. Acesso em: 16 mar. 2021.

MARQUES, Ana P. "Novas" legitimidades de segmentação do mercado de trabalho de jovens diplomados. Revista Portuguesa de Educação, Universidade do Minho, 2009, 22(2), p. 85-115. Disponível em: http://www.scielo.mec.pt/pdf/rpe/v22n2/v22n2a05.pdf. Acesso em: 16 mar. 2021.

MARQUES, Ana P. P. Na fronteira do mercado de emprego: jovens, trabalho e cidadania. Trab. educ. saúde, Rio de Janeiro, v. 18, supl. 1, 2020. Disponível em: <http://www.scielo.br/scielo.php?script=sci_arttext\&pid=S198177462020000400501\&lng=pt\&nrm=iso>. Acesso em: 15 mar. 2021.

MARTINS, Felipe S.; MACHADO, Danielle C. Uma análise da escolha do curso superior no Brasil. Rev. bras. estud. popul., São Paulo, v. 35, n. 1, 2018. Disponível 
em: http://www.scielo.br/scielo.php?script=sci_arttext\&pid=S010230982018000100155\&lng=en\&nrm=iso. Acesso em: 27 mar. 2021.

MINARELLI, José A. Empregabilidade: Como entrar, permanecer e progredir no mercado de trabalho. $25^{\text {a }}$ edição. São Paulo: Gente, 2010.

MONTEIRO, Mariana S. H.; LEITE, Diogo B. Perspectivas de carreira dos estudantes de administração da Universidade Federal de Mato Grosso: comparativo entre estudantes de gerações X e Y. Navus - Revista de Gestão e Tecnologia. v. 9, n. 1, p. 87-104, fev. 2019. Disponível em: http://navus.sc.senac.br/index.php/navus/article/view/780. Acesso em: 7 jan. 2021.

MOREIRA, Fábio M.; QUEIROZ, Timóteo R.; MACINI, Nayele; CAMPEÃO, Gabriela H. Os alunos de administração estão em sintonia com o mercado de trabalho? Avaliação (Campinas), Sorocaba, v. 19, n. 1, p. 61-88, Mar. 2014. Disponível em: http://www.scielo.br/scielo.php?script=sci_arttext\&pid=S141440772014000100004\&lng=en\&nrm=iso. Acesso em: 15 mar. 2021.

MORESI, Eduardo. Metodologia da Pesquisa. Brasília: Universidade Católica de Brasília, Mar. 2003. Disponível em: https://s3.amazonaws.com/academia.edu.documents/34168313/MetodologiaPesquisa-

Moresi2003.pdf?response-content-

disposition=inline\%3B\%20filename\%3DMetodologia_da_Pesquisa_PRO-

REITORIA_DE.pdf\&X. Acesso em: 5 abr. 2020.

MOURA, Cynthia B.; MENEZES, Mirtes V. Mudando de opinião: análise de um grupo de pessoas em condição de re-escolha profissional. Rev. bras. orientac. prof., São Paulo, v. 5, n. 1, p. 29-45, jun. 2004. Disponível em: http://pepsic.bvsalud.org/scielo.php?script=sci arttext\&pid=S1679-

33902004000100004\&lng=pt\&nrm=iso . Acesso em: 27 mar. 2021.

NIPPON.COM. Sociedade. La mano de obra extranjera, cada dia más necesaria en un Japón que envejece. 20 ago. 2018. Disponível em https://www.nippon.com/es/features/h00242/. Acesso em: 20 abr. 2021.

OLIVEIRA, Lucia B. Percepções e estratégias de inserção no trabalho de universitários de Administração. Rev. bras. orientac. prof. São Paulo, v. 12, n. 1, p. 8395, jun. 2011. Disponível

http://pepsic.bvsalud.org/scielo.php?script=sci_arttext\&pid=S167933902011000100010\&lng=pt\&nrm=iso. Acesso em: 7 jan. 2021.

OLIVEIRA, Lucia B.; HONORIO, Shanna R. F. S. Atração e desligamento voluntário de jovens empregados: um estudo de caso no setor jornalístico. Rev. Adm. (São Paulo), São Paulo, v. 49, n. 4, p. 714-730, dez. 2014. Disponível em: http://www.scielo.br/scielo.php?script=sci_arttext\&pid=S0080-

21072014000400714\&lng=pt\&nrm=iso. Acesso em: 19 mar. 2021.

OLIVEIRA, Marina C.; DETOMINI, Vitor C.; MELO-SILVA, Lucy L. Sucesso na transição universidade-trabalho: expectativas de universitários formandos. Psicologia em Revista, Belo Horizonte, v. 19, n. 3, p. 497-518, dez. 2013. Disponível em: file:///D:/Users/Meu\%20Not/Downloads/3261-Texto\%20do\%20artigo-25825-1-1020140310.pdf. Acesso em: 14 jul. 2020. 
OLIVEIRA, Sidinei R.; PICCININI, Valmiria C.; SILVEIRA, Cássia S. O trabalho como representação: a visão dos jovens universitários. Revista de Ciências da Administração, Florianópolis, p. 171-197, jan. 2010. Disponível em: https://periodicos.ufsc.br/index.php/adm/article/view/2175-8077.2010v12n28p171.

Acesso em: 14 jul. 2020.

PIETROVSKI, Eliane F.; SCHNEIDER, Elton I.; REIS, Dálcio R.; REIS JÚNIOR, Dálcio R. Análise do potencial empreendedor em alunos do ensino superior: aplicação da teoria à prática. Innovar, Bogotá, v. 29, n. 71, p. 25-42, Mar. 2019. Disponível em: http://www.scielo.org.co/scielo.php?script=sci_arttext\&pid=S0121-

50512019000100025\&lng=en\&nrm=iso. Acesso em: 15 mar. 2021.

PRONI, Thaíssa T. R. W.; PRONI, Marcelo W. Discriminação de gênero em grandes empresas no Brasil. Rev. Estud. Fem., Florianópolis, v. 26, n. 1, 2018. Disponível em: http://www.scielo.br/scielo.php?script=sci_arttext\&pid=S0104-

026X2018000100212\&lng=pt\&nrm=iso. Acesso em: 05 nov. 2020.

RAMOS, Madalena; PARENTE, Cristina; SANTOS, Mónica. Os licenciados em Portugal: uma tipificação de perfis de inserção profissional. Educ. Pesqui. [online]. 2014, v. 40, n.2, p. 383-400. Disponível em: https://www.scielo.br/scielo.php?pid=S1517-

97022014005000001\&script=sci_abstract\&tlng=pt . Acesso em: 06 de mai. 2020.

RIBEIRO, Carla V. S.; LÉDA, Denise B. O significado do trabalho em tempos de reestruturação produtiva. Estudos e Pesquisa em Psicologia, Rio de Janeiro, Ano 4, n. 2, 2004. Disponível em: http://www.revispsi.uerj.br/v4n2/artigos/ARTIGO5V4N2.pdf. Acesso em: 05 nov. 2020.

RIBEIRO, Marcelo A. Juventude e trabalho: construindo a carreira em situação de vulnerabilidade. Arq. bras. psicol., Rio de Janeiro, v. 63, n. spe, p. 58-70, 2011. Disponível em: http://pepsic.bvsalud.org/scielo.php?script=sci_arttext\&pid=S180952672011000300007\&lng=pt\&nrm=iso. Acesso em: 18 mar. 2021.

RUEDA, Fabián J. M.; MARTINS, Luciana J.; CAMPOS, Keli C. L. Empregabilidade: o que os alunos universitários entendem sobre isto? Revista Psicologia -Teoria e Prática, v. 6, ed. 2, p. 63-73, 2004. Disponível em: file:///C:/Users/Vivi/Downloads/1165-Texto\%20do\%20artigo-3256-1-1020090728.pdf. Acesso em: 5 mai. 2020.

SILVA, Mara. R. R. Mulheres no comando: Uma revisão na literatura sobre liderança feminina no campo do trabalho no Brasil. Revista Estudos e Pesquisas em Administração -Repad, v. 4, n. 3, p 147-169, set./dez. 2020. Disponível em: https://periodicoscientificos.ufmt.br/ojs/index.php/repad/article/view/10902/7584.

Acesso em: 27 mar. 2021.

SIQUEIRA, Rafaela F. B.; MIRANDA, Adílio R. A.; CAPPELlE, Mônica C. A. Mulheres na gestão universitária: a ótica de docentes de Minas Gerais. Revista Gestão Universitária na América Latina, v.12, n. 2, p. 48-71, mai. 2019. Disponível em: https://periodicos.ufsc.br/index.php/gual/article/view/1983-4535.2019v12n2p48.

Acesso em: 27 mar. 2021.

TOMMASI, Lívia; CORROCHANO, Maria C. Do qualificar ao empreender: políticas de trabalho para jovens no Brasil. Estud. av., São Paulo, v. 34, n. 99, p. 353-372, 
ago. 2020.

Disponível

em:

http://www.scielo.br/scielo.php?script=sci_arttext\&pid=S0103-

40142020000200353\&lng=pt\&nrm=iso. Acesso em: 15 mar. 2021.

VALE, Gláucia V.; WILKINSON, John; AMÂNCIO, Robson. Empreendedorismo, inovação e redes: uma nova abordagem. RAE-eletrônica, v. 7, n. 1, Art. 7, jan./jun. 2008. Disponível em: https://www.scielo.br/pdf/raeel/v7n1/a08v7n1.pdf. Acesso: 15 mar. 2021.

VARGAS, Hustana M.; PAULA, Maria F. C. A inclusão do estudante-trabalhador e do trabalhador-estudante na educação superior: desafio público a ser enfrentado. Avaliação (Campinas), Sorocaba, v. 18, n. 2, p. 459-485, Jul. 2013. Disponível em: http://www.scielo.br/scielo.php?script=sci_arttext\&pid=S1414-

40772013000200012\&lng=en\&nrm=iso. Acesso em: 18 mar. 2021.

VIEIRA, Diana A.; MARQUES, Ana P. Preparados para trabalhar? Um estudo com diplomados do ensino superior e empregadores. Porto: Consórcio Maior Empregabilidade, Instituto Politécnico do Porto, 2014. Disponível em: http://repositorium.sdum.uminho.pt/bitstream/1822/49890/1/\%282014\%29Preparados\% 20para\%20Trabalhar.pdf. Acesso em: 16 mar. 2021. 